\title{
A construal-level approach to hedonic and utilitarian shopping orientation
}

\author{
Daniele Scarpi ${ }^{1}$ (i)
}

Accepted: 3 January 2021 /Published online: 25 January 2021

(C) The Author(s) 2021

\begin{abstract}
Several studies in consumer behavior have focused on consumers' shopping orientation in terms of hedonic and utilitarian shopping. The present research advances a different perspective examining hedonic and utilitarian shopping orientations with the theoretical lenses of construal-level theory. Results from two studies indicate that hedonism relates to higher and utilitarianism to lower construal levels (Study 1). Consequently, individuals tend to prefer desirability-related options when shopping hedonically, and feasibility-related options when shopping in a utilitarian way (Study 2). The findings further show a moderating effect of construal level on the relationship between shopping orientation and choice, consistent with construal-level theory.
\end{abstract}

Keywords Shopping orientation · Hedonism · Utilitarianism · Construal level

\section{Introduction}

Several studies in consumer behavior have focused on how consumers shop, identifying cases where consumers shop for need, alongside a "shopping as work" theme (Babin et al. 1994), and other cases where shopping is instead a joy, alongside a "shopping for fun" theme (Holbrook and Hirschman 1982). These shopping orientations refer to consumers' general predisposition toward the act of shopping and are usually discussed in terms of "goal-oriented" or "utilitarian" and "recreational" or "hedonic" (see Scarpi 2012, for a review). Their contrast illustrates a heterogeneity in consumers' subjective way of experiencing a shopping expedition, yet studies have mostly neglected to focus on consumers' mindsets in studying shopping orientation.

To this purpose, we posit that construal-level theory (Trope and Liberman 2010) could provide a possible interpretative key. Construal-level theory distinguishes between two levels of mental representation that individuals may hold about the

Daniele Scarpi

daniele.scarpi@unibo.it

1 Department of Management, University of Bologna, Bologna, Italy 
surrounding reality: low construal and high construal. Low construal emphasizes psychological closeness and focuses on concreteness and feasibility; high construal emphasizes psychological distance and focuses on abstractness and desirability. Construal levels capture how individuals evaluate and categorize (Liberman et al. 2002), choose (Liberman et al. 2007b), and remember objects (Liberman et al. 2007a). Accordingly, construal-level theory has been shown to account for a variety of differences in behavior exhibited by consumers. For example, construal can influence which features consumers value in product choice (Trope and Liberman 2010), how they mentally organize (Lee et al. 2014), evaluate products (Lamberton and Diehl 2013), react to color (Lee et al. 2014), and music (Hansen and Melzner 2014).

The current research aims to advance a novel understanding of how construal also influences consumers' shopping orientation. We ask, is it possible that the construal that an individual adopts influences a fundamental aspect of the shopping process - the hedonic and utilitarian shopping orientation through which a shopping trip is processed and experienced? The answer to this question holds a wealth of information because a considerable stream of literature has recognized which orientation consumers adopt when shopping as being of key importance (Holbrook and Hirschman 1982; Scarpi 2012). Does construal level influence consumers' shopping orientation? Symmetrically, does shopping in a hedonic or utilitarian way lead to the adoption of a different level of construal?, and do different construal-induced shopping orientations affect which options consumers choose from the same choice set?

\section{Theoretical background}

Mental representations of the objects around oneself affect how the surrounding reality is interpreted (Liberman et al. 2007a). These mental representations are usually discussed in terms of high and low construal levels. They are powerful mechanisms that drive how people mentally construe objects and events, and they affect how and what individuals evaluate, interpret, and even remember of the surrounding reality (Liberman et al. 2007a). Specifically, high levels of construal capture abstract, schematic, global, superordinate features of an object, focus on the value of an action's end state, and facilitate attitude-based and selective information processing. Low levels of construal, on the other hand, incorporate concrete, specific, peripheral, contextual, subordinate features, focus on the means used to reach the end state, and facilitate attribute-based and comparative processing (Trope and Liberman 2010; Kardes 2013; Pfeiffer et al. 2014).

Consequently, construal levels are important also in that their activation shifts behavior. For instance, the activation of high-level construal shifts weight from lowlevel features to high-level features, thus increasing the relevance of the desirability of an outcome rather than the feasibility of the means necessary to achieve that outcome. Therefore, individual choices under the adoption of higher construal tend to be driven mainly by desirability-related considerations, whereas feasibility-related considerations emerge when the same choice situation is envisioned under the perspective of a lower construal (Liberman and Trope 1998).

A separate stream of literature has instead addressed shopping orientation and how it affects individuals' behavior while shopping or browsing. Specifically, the literature 
identifies a hedonic and a utilitarian shopping orientation: Hedonism is the festive, ludic side of shopping; it is related to enjoyment and playfulness rather than to task completion, and encompasses pleasure, curiosity, escapism, and fun (Babin et al. 1994; Griffin et al. 2000). Utilitarianism by contrast represents a task-related, ergic shopping orientation, where products are purchased "efficiently" and consumers describe the shopping experience in terms of performance evaluation (e.g., quick; accomplishment). In summary, hedonism is related to joy and fun, to shopping not because of the need for a specific item but for more abstract reasons pertaining to escapism, exploration, and fantasizing that transcend the physical characteristics of the products. Utilitarianism instead refers to those cases where individuals seek an item in particular and evaluate the tangible features of products in an efficiency-maximizing, here-and-now experience (Scarpi 2012).

To the best of the authors' knowledge, no previous research has related shopping orientation to construal, yet a number of considerations and previous findings would hint at the possibility of such a relationship. For instance, Liberman et al. (2002) found that individuals adopting a functional or task-oriented approach to problem-solving adopt a low level of abstraction perspective, while Jones et al. (2006) defined abstract, higher-order characteristics of goods as "monovalent satisfiers" and related them to hedonism. Given the task-orientedness of utilitarianism (Scarpi 2012) and the higher construal of abstractness (Liberman and Trope 1998), one could argue a relationship between hedonism (utilitarianism) and higher (lower) construal.

Furthermore, in revising shopping orientation adopting a regulatory-focus perspective, Ashraf et al. (2016) found that promotion- (prevention-) focused individuals tend to browse with a hedonic (utilitarian) orientation. Consistently, previous research related the hedonic (utilitarian) benefits of purchasing a product to the adoption of a promotion (prevention) focus (Roy and $\mathrm{Ng}$ 2012). In turn, studies on construal-level theory related high (low) construal levels to a promotion (prevention) focus (Eyal et al. 2004; Pennington and Roese 2003).

Overall, we posit that these findings and considerations suggest an effect of hedonism (utilitarianism) on construal level. Specifically, in the present research, we link the shopping orientation of individuals to their mental representations in terms of construal level. To the best of our knowledge, we are the first to advance such a link. Specifically, we posit that hedonic (utilitarian) shopping leads to the adoption of higher (lower) construal levels and that, vice versa, activation of high (low) construal level leads individuals to shop with a hedonic (utilitarian) orientation. In turn, depending on which construal level they adopt, individuals will choose different products from the same set of options. Specifically, we posit that hedonism (utilitarianism) leads to choosing more desirability- (feasibility-) related options, through the activation of a higher (lower) construal level.

Finally, it might be worth highlighting the difference between hedonism and desirability. Hedonism refers to fantasizing while shopping, feeling enjoyment, being immersed in the here and now of the store; it follows that hedonic products are those whose consumption or purchase provides pleasure, fun, and enjoyment (Dhar and Wertenbroch 2000). Instead, desirability in CLT terms is not related to fun or escapism, but to abstractness - specifically, the value of the action's end state (Trope and Liberman 2010), yet such value can be either hedonic or utilitarian (Babin et al. 1994; Griffin et al. 2000); likewise, both hedonic and utilitarian products can be 
desirable, as neither construct is aligned with valence (Botti and McGill 2011). Furthermore, the CLT literature associates the "heart" with low construal and the "mind" with high construal (Septianto and Pratiwi 2016), which are, in turn, related to feasibility and desirability, respectively (Liberman and Trope 1998), yet in the shopping orientation literature, hedonism has been related to the heart and utilitarianism to the mind (e.g., Shiv and Fedorikhin 1999; Dhar and Wertenbroch 2000; Melnyk et al. 2012), as the former relates to feelings and fantasies, while the latter relates to value-calculation and efficiency maximization.

A different literature stream, which classifies products into "want" or "should," provides a similar conclusion about the lack of equivalence between hedonism and desirability (Milkman et al. 2008). The "want" products have been related to hedonism (Chitturi et al. 2008) and low construal (Milkman et al. 2008), while the "should" products have been related to utilitarianism and high construal. If hedonism and desirability were closely related, the association would be flipped, as desirability is reflective of a high construal level according to CLT (Liberman and Trope 1998). Overall, "want" or "should" products are not more or less desirable per se (Fujita et al. 2006), as hedonic and utilitarian products can be equally desirable despite the different values underlying their purchase (Botti and McGill 2011; Scarpi 2012).

\section{Studies}

To establish the link between shopping orientation and construal level, we run two experiments. First, we demonstrate that individuals who envision the shopping experience under a higher (lower) construal are more likely to adopt a hedonic (utilitarian) approach to shopping (study 1). Next (study 2), we show that individuals prefer desirability (feasibility) related options when they shop hedonically (utilitarianistically). Then, we show the presence of a partial mediation effect of construal level on the relationship between shopping orientation and choice. Finally, we provide a follow-up study in a natural setting on actual consumers and choices.

For both studies, the scales satisfy standard requirements, with Cronbach's alphas ranging between 0.70 and 0.91 , and the composite reliability (CR) and the average variance extracted (AVE) no lower than the recommended 0.70 and 0.50 thresholds, respectively (Fornell and Larcker 1981). Details are in the Appendix.

\subsection{Study 1: construal level $\rightarrow$ hedonism}

\subsubsection{Method}

A total of 110 respondents were gathered from a panel (47\% women; mean age $=31$; median age $=29$ ) for an online-implemented survey. First, respondents were randomly assigned to one of two images that served as construal-level priming. The images depicted a road with a downward-pointing arrow far from (for high construal) or near to (for high construal) the respondents, as in Hansen and Wänke (2010). Next, participants completed Lee et al. (2014) shortened version of the Behavioral Identification Form (BIF) (Vallacher and Wegner 1989) to measure construal level, as also advised by the developers of CLT (Liviatan et al. 2008; Nissan et al. 2015). 
The shortened BIF consists of a random subset of eight of 19 neutrally described actions, each followed by two alternative restatements: one corresponding to the "how" or low-level aspects, and one to the "why" or high-level aspects (e.g., a neutral action: "reading" can be restated either in low-construal terms as "following lines of print" or in high-construal terms as "gaining knowledge"). As in Vallacher and Wegner (1989) and Lee et al. (2014), a score of 0 (1) was imputed if consumers chose the low- (high-) level restatement. Accordingly, BIF score ranges from 0 (completely low-level) to 8 (completely high-level; Liberman et al. 2007b).

Participants saw a retailer's website and were asked to imagine they were shopping. Then, they were asked 7-point scales for hedonism and utilitarianism by Scarpi (2012), and retailer familiarity (Edwards et al. 2009). Furthermore, previous literature suggested that construal-level manipulations might induce mood (Fujita et al. 2006; Labroo and Patrick 2009). Thus, to rule out mood-based alternative explanations, respondents answered also the PANAS scale for mood by Watson et al. (1988), as in Fujita et al. (2006) and Massara et al. (2020). Finally, after reporting their age and gender, participants were tested for suspicion, thanked, and debriefed. Items are reported in the Appendix.

\subsubsection{Results}

Results from the manipulation check support the manipulation of construal level: respondents exposed to high-level priming displayed higher BIF scores $\left(M_{\mathrm{High}}=4.35\right)$ than those exposed to low-level priming $\left(M_{\text {Low }}=3.39, F_{(1,109)}=5.79, p=0.02, \eta^{2}=0.05\right)$.

Consistent with our predictions, an analysis of variance (ANOVA) with construal level as independent variable, and hedonism, utilitarianism, familiarity with the retailer as dependent variables, shows that individuals adopting a high-level construal score higher on hedonism than those adopting a low-level construal $\left(M_{\mathrm{High}}=4.32, \mathrm{SD}=1.26\right.$ vs. $\left.M_{\text {Low }}=3.67, \mathrm{SD}=1.35, F_{(1,108)}=5.85, p=0.02 ; \eta^{2}=0.05\right)$, and lower on utilitarianism $\left(M_{\mathrm{High}}=4.64, \mathrm{SD} 1.38\right.$ vs. $M_{\mathrm{Low}}=5.20, \mathrm{SD}=1.28, F_{(1,108)}=4.50, p=$ $\left.0.36, \eta^{2}=0.04\right)$.

No differences emerged for retailer familiarity $\left(M_{\text {High }}=5.61, \mathrm{SD}=1.38\right.$ vs. $M_{\text {Low }}=$ $\left.5.87, \mathrm{SD}=1.31, F(1,109)=0.86, p=0.36 ; \eta^{2}=0.01\right)$, positive $\operatorname{mood}\left(M_{\mathrm{High}}=3.50, \mathrm{SD}=\right.$ 1.07 vs. $\left.M_{\text {Low }}=3.50, \mathrm{SD}=1.04, F_{(1,109)}=0.01, p=0.98 ; \eta^{2}=0.01\right)$, or negative mood $\left(M_{\text {High }}=1.87, \mathrm{SD}=0.73\right.$ vs. $M_{\text {Low }}=1.96, \mathrm{SD}=0.76, F_{(1,109)}=0.34, p=0.56 ; \eta^{2}=$ $0.001)$, thus ruling out familiarity-, difficulty-, and mood-related alternative explanations.

\subsection{Study 2: hedonism $\rightarrow$ construal level}

Study 1 established the construal-hedonism relationship to answer the question of whether construal level influences consumers' shopping orientation. To do so, study 1 primed construal and measured the level of hedonism. As detailed in the theoretical background, CLT encompasses a bidirectionality principle. Accordingly, study 2 reverses the independent and dependent variables to demonstrate the bidirectional influences. Thus, it primes hedonism and measures the level of construal.

Furthermore, study 2 examines which products individuals choose. Specifically, previous research established that individuals tend to prefer desirability-related options 
when adopting high construal, and feasibility-related options for low construal (Liberman and Trope 1998; Kardes et al. 2006). Accordingly, STUDY 2 compared choice shares for options that are more feasible than desirable, and options that are more desirable than feasible (as detailed below). Furthermore, a mediation analysis tests whether the relationship between shopping orientation and choice transits through construal level.

\subsubsection{Method}

A total of 275 participants were recruited from an online panel (50\% females; mean age $=33$ ). Participants were primed for hedonism and utilitarianism by means of a short verbal text whose wording was based on the respective scale's items. Next, they were shown lotteries to choose from. Lotteries can be envisioned in terms of feasibility (odds of winning) or desirability (jackpot) (Sagristano et al. 2002). Payoffs are more relevant under low construal, and probability more relevant under high construal. Based on Sagristano et al. (2002), the lotteries emphasized-respectively-desirability and feasibility. Respondents were asked to choose one lottery, answered the items measuring construal level, shopping orientation, age, and gender.

\subsubsection{Results and discussion}

Hedonic priming increased the level of hedonism $\left(M_{1}=4.76, \mathrm{SD}=1.27\right.$ vs. $\left.M_{2}=3.92, \mathrm{SD}=1.17, F_{(1,272)}=14.43, p<0.001 ; \eta^{2}=0.05\right)$, and utilitarian priming increased the level of utilitarianism $\left(M_{1}=4.51, \mathrm{SD}=1.37\right.$ vs. $M_{2}=$ 4.04, $\left.\mathrm{SD}=1.66, F_{(1,272)}=16.02, p<0.001 ; \eta^{2}=0.05\right)$.

In line with our expectations, an ANOVA revealed that consumers with prevalently hedonic (utilitarian) shopping orientation exhibited higher (lower) levels of construal as measured by the BIF score $\left(M_{\mathrm{Hedo}}=4.69, \mathrm{SD}=1.67\right.$ vs. $M_{\mathrm{Uti}}=3.95, \mathrm{SD}=1.45, F_{(1}$, 272) $\left.=15.41, p<0.001 ; \eta^{2}=0.05\right)$. A chi-square test of independency was calculated comparing the frequency of preference for the desirability- (feasibility-) related lotteries among respondents with a predominantly hedonic or utilitarian shopping orientation. A significant interaction was found $\left(\chi^{2}(1)=4.57, p=0.02\right)$, highlighting that consumers shopping in a hedonically (utilitarianistically) were more likely to choose desirability(feasibility-) related options.

Finally, a mediation analysis was run with the PROCESS macro in SPSS by means of 5000 bootstrap samples to create bias-corrected confidence intervals (CIs; 95\%; model 4, Hayes 2018). Results provide support for a full mediation of construal level on the shopping orientation - choice relationship, with a significant mediation index (effect $=0.07$, se $=0.04 ;[0.01,0.15]$ ) as the confidence interval does not contain zero (Hayes 2018). Specifically, hedonism increases construal level (effect $=0.37$, se $=0.09$, $t=3.97, p<0.001$ ), with high (low) construal level affecting choice for the desirability(feasibility-) related options (effect $=0.20$, se $=0.08, t=2.41, p=0.02$ ), and shopping orientation not exerting a significant direct effect on choice $(p=0.13)$.

In summary, hedonic (utilitarian) shopping orientation increases (decreases) construal level, leading consumers to choose the more desirable (feasible) options, at the expense of feasibility (desirability). 


\subsection{Follow-up study}

A follow-up study was run offline with 150 customers $(53 \%$ women; median age $=37$ ) who received a paper-and-pencil questionnaire in a shopping mall. The response rate was high $(83 \% ; 180$ contacted), as respondents were interviewed while queuing at the cashier, as in Scarpi (2020). We measured shoppers' demographics, shopping orientation, construal level, retailer familiarity, and mood, as in study 1a, but also the desirability of the purchase experience, store and products (Vogt and Andereck 2003), and how much money they had spent (see the Appendix). All respondents had made at least one purchase.

\subsubsection{Results and discussion}

A CFA run in AMOS 25 confirms that hedonism, utilitarianism, desirability, price consciousness, decision satisfaction, pleasure, and arousal load on seven distinct factors (Chisquare $/ \mathrm{df}=1.62, \mathrm{CFI}=0.91, \mathrm{RMSEA}=0.06$ ). As a further test of discriminant validity, the minimum AVE exceeds the squared correlation between the two variables (Fornell and Larcker 1981). Furthermore, desirability did not differ based on shopping orientation $\left(M_{\mathrm{Uti}}=5.10, S D=0.99\right.$ vs. $\left.M_{\mathrm{Hedo}}=5.32, \mathrm{SD}=1.17 ; F_{(1,146)}=1.32, p=0.25, \eta^{2}=0.01\right)$.

In line with the evidence from the previous studies, ANOVAs reveal that consumers displaying higher levels of hedonism also adopted a higher construal level, as reflected in the higher $\mathrm{BIF}$ score $\left(M_{\mathrm{Low}}=3.82, \mathrm{SD}=1.84\right.$ vs. $M_{\mathrm{High}}=4.63, \mathrm{SD}=1.60 ; F_{(1,146)}=6.33, p=$ $\left.0.01, \eta^{2}=0.04\right)$. Furthermore, those who shopped hedonically spent more money $\left(M_{\mathrm{Uti}}=\right.$ $60.15, \mathrm{SD}=26.99$ vs. $\left.M_{\text {Hedo }}=71.72, \mathrm{SD}=27.33 ; F_{(1,146)}=4.66, p=0.03, \eta^{2}=0.03\right)$. Comparing the amount of money spent for those with a high and low construal level (median spit; median $=4$ ) shows a significant relationship that aligns with the previous studies $\left(M_{\text {Low }}=57.15, \mathrm{SD}=26.47\right.$ vs. $M_{\text {High }}=74.85, \mathrm{SD}=24.69 ; F_{(1,148)}=17.09$, $p<0.001, \eta^{2}=0.07$ ).

A mediation analysis in PROCESS supported the partial mediation of construal level on the shopping orientation-amount-spent relationship, with a significant mediation index (effect $=0.08, \mathrm{se}=0.05 ;[0.01,0.21])$. Specifically, hedonic shopping orientation increases construal level (effect $=0.81$, se $=0.32, t=2.52, p=0.01$ ), with a higher construal level increasing the amount of money spent (effect $=0.10$, se $=0.05, t=$ $2.22, p=0.03$ ), while shopping orientation exerts a marginally significant direct effect on the amount spent (effect $=0.31$, se $=0.18, t=1.68, p=0.09$ ).

Again, no differences emerged for retailer familiarity $(p=0.72)$ or mood (positive: $p=0.48$; negative: $p=0.23$ ) due to shopping orientation.

\section{Discussion}

This research makes two theoretical contributions. The first is to the literature on shopping orientation: it advances the understanding of the differences between hedonic and utilitarian shopping orientation (Babin et al. 1994), by focusing not on products or shopping environments (Klein and Melnyk 2016) but on the mindset of the consumers. It demonstrates that consumers shopping hedonically construe information at a more abstract level than those shopping in a utilitarian way. This allows us to reinterpret 
previous findings from a different perspective. For instance, Smith et al. (2005) found that consumers shopping in a utilitarian way listened to recommendations from peers they would identify with. Those shopping hedonically, by contrast, listened to recommendations from socially distant experts. Although they did not aim at providing a rationale, our evidence allows us to do so: lower (higher) social distance triggers a lower (higher) construal level (Liberman et al. 2002) that relates to utilitarianism (hedonism). Results may generalize to preferences for hedonic versus utilitarian goods, as well as for shopping orientations.

The second contribution of this research is to construal-level theory: it identifies shopping orientation as an antecedent of the construal that individuals adopt to process information in making a choice, advancing the knowledge of elements that influence construal (e.g., Hansen and Melzner 2014; Lee et al. 2014; Slepian et al. 2015).

Adopting the theoretical lenses of construal-level theory, this research complements and enriches previous findings on shopping orientation. For instance, it helps explain why Jones et al. (2006) found abstract satisfiers to relate to hedonism, why intrinsic (extrinsic) motivation predicted usage for utilitarian (hedonic) systems (van der Heijden 2004), or why consumers shopping in a hedonic (utilitarian) way adopt a promotion (prevention) focus (Ashraf et al. 2016; Roy and Ng 2012). Specifically, abstractness, extrinsic motivation, and promotion focus are high-construal-related features, whereas concreteness (Trope and Liberman 2010), intrinsic motivation (Hansen and Trope 2013), and prevention focus are low-construal-related features (Eyal et al. 2004).

Future research should examine other downstream consequences of the relationship between construal level and shopping orientation that could be relevant for marketers. For example, is it possible that hedonism makes consumers more likely to buy products presented by benefits and more accepting of ads that use abstract language, given that a benefit-based layout (Lamberton and Diehl 2013) and abstractly worded ads (Massara et al. 2020) increase construal level?

A favorable response to similar questions is likely to require flexibility from practitioners, as it necessitates the ability to profile consumers and - for instance - to manage shopping atmospherics in order to induce either a hedonic or a utilitarian shopping orientation. Previous research suggests that such targeting is possible (Mehta and Dixit 2016), but the construal-level-related logic outlined above provides further novel implications for future research. For instance, sorting criteria have been found to be a function of construal level (Trope and Liberman 2010). Thus, one could expect that shopping orientation also affects how consumers mentally categorize a retailer's assortment. This logic could be further extended to the considerations of other features that practitioners could implement in a store, and that previous literature has related to construal level, such as music (Hansen and Melzner 2014), product color (Lee et al. 2014), and vertical or horizontal layout (Slepian et al. 2015). Future research could address these elements as moderators or boundary conditions of the findings from the present analysis.

Furthermore, it should be noted that shopping orientations can vary over time, even from one shopping expedition to the next (Babin et al. 1994). As a consequence, consumers' preferences could change, and consumers could regret their choices. For instance, consumers could weight desirability heavily initially but weight more heavily feasibility later in time. Such change would lead to incompatible choices and could lead consumers, ultimately, to regret earlier choices (Grigsby et al. 2020). 
Finally, previous research found Americans to be more abstractly minded than Chinese consumers (Spassova and Lee 2013). Thus, future studies could relate cultural differences in shopping orientation (Griffin et al. 2000; Lim and Ang 2008) to those in construal level.

In conclusion, this research uncovers a novel relationship between shopping orientation and construal-level theory, suggesting that individuals shopping in a hedonic (utilitarian) orientation construe information at a higher (lower) level of construal, and that - symmetrically - higher (lower) construal levels are more likely to lead to a hedonic (utilitarian) shopping orientation. The findings reveal a wealth of information about consumers' processing of products' information and offer intriguing avenues for future investigation.

However, although construal level theory predicts bidirectionality among all dimensions of psychological distance, spatial distance has been found to be less symmetrical, that is, it increases perceived distance on the other three dimensions of psychological distance, but not vice versa (Zhang and Wang 2009). This might be because spatial distance is easier to interpret, relative to the other dimensions, and consumers might use it to understand distances on the other dimensions. However, it implies that symmetric, bidirectional, relationships among the four dimensions of psychological distance are not always observable.

Supplementary Information The online version contains supplementary material available at https://oi.org/ 10.1007/s11002-021-09558-8.

Funding information Open Access funding provided by Alma Mater Studiorum - Università di Bologna.

Open Access This article is licensed under a Creative Commons Attribution 4.0 International License, which permits use, sharing, adaptation, distribution and reproduction in any medium or format, as long as you give appropriate credit to the original author(s) and the source, provide a link to the Creative Commons licence, and indicate if changes were made. The images or other third party material in this article are included in the article's Creative Commons licence, unless indicated otherwise in a credit line to the material. If material is not included in the article's Creative Commons licence and your intended use is not permitted by statutory regulation or exceeds the permitted use, you will need to obtain permission directly from the copyright holder. To view a copy of this licence, visit http://creativecommons.org/licenses/by/4.0/.

\section{References}

Ashraf, A. . R., Razzaque, M. A., \& Thongpapanl, N. T. (2016). The role of customer regulatory orientation and fit in online shopping across cultural contexts. Journal of Business Research, 69(12), 6040-6047.

Babin, B. . J., Darden, W. R., \& Griffin, M. (1994). Work and/or fun: measuring hedonic and utilitarian shopping value. Journal of Consumer Research, 20(4), 644-656.

Botti, S., \& McGill, A. L. (2011). The locus of choice: personal causality and satisfaction with hedonic and utilitarian decisions. Journal of Consumer Research, 37(6), 1065-1078.

Chitturi, R., Raghunathan, R., \& Mahajan, V. (2008). Delight by design: the role of hedonic versus utilitarian benefits. Journal of Marketing, 72(3), 48-63.

Dhar, R., \& Wertenbroch, K. (2000). Consumer choice between hedonic and utilitarian goods. Journal of Marketing Research, 37(1), 60-71.

Edwards, S.M., Lee, J.K., and Ferle, C.L. (2009). Does place matter when shopping online? Perceptions of similarity and familiarity as indicators of psychological distance. Journal of Interactive Advertising, 10(1), 35-50.

Eyal, T., Liberman, N., Trope, Y., \& Walther, E. (2004). The pros and cons of temporally near and distant action. Journal of Personality and Social Psychology, 86(6), 781-795. 
Fornell, C., \& Larcker, D. F. (1981). Evaluating structural equation models with unobservable variables and measurement error. Journal of Marketing Research, 18(1), 39-50.

Fujita, K., Trope, Y., Liberman, N., \& Levin-Sagi, M. (2006). Construal levels and self-control. Journal of Personality and Social Psychology, 90(3), 351-367.

Griffin, M., Babin, B. . J., \& Modianos, D. (2000). Shopping values of Russian consumers: the impact of habituation in a developing economy. Journal of Retailing, 76(1), 33-52.

Grigsby, J. L., Jewell, R. D., \& Campbell, C. (2020). Have your cake and eat it too: how invoking postpurchase hyperopia mitigates impulse purchase regret. Marketing Letters, 1-15.

Hansen, J., \& Melzner, J. (2014). What you hear shapes how you think: sound patterns change level of construal. Journal of Experimental Social Psychology, 54, 131-138.

Hansen, J., \& Trope, Y. (2013). When time flies: How abstract and concrete mental construal affect the perception of time. Journal of Experimental Psychology: General, 142(2), 336-347.

Hansen, J., \& Wänke, M. (2010). Truth from language and truth from fit: the impact of linguistic concreteness and level of construal on subjective truth. Personality and Social Psychology Bulletin, 36(11), 15761588.

Hayes, A. F. (2018). Introduction to mediation, moderation, and conditional process analysis second edition: A regression-based approach. New York, NY: The Guilford Press.

Holbrook, M. B., \& Hirschman, E. C. (1982). The experiential aspects of consumption: consumer fantasies, feelings, and fun. Journal of Consumer Research, 9(2), 132-140.

Jones, M. A., Reynolds, K. E., \& Arnold, M. J. (2006). Hedonic and utilitarian shopping value: investigating differential effects on retail outcomes. Journal of Business Research, 59(9), 974-981.

Kardes, F. R., Cronley, M. L., \& Kim, J. (2006). Construal-level effects on preference stability, preferencebehavior correspondence, and the suppression of competing brands. Journal of Consumer Psychology, $16(2), 135-144$.

Kardes, F. R. (2013). Selective versus comparative processing. Journal of Consumer Psychology, 23(1), 150153.

Klein, K., \& Melnyk, V. (2016). Speaking to the mind or the heart: effects of matching hedonic versus utilitarian arguments and products. Marketing Letters, 27(1), 131-142.

Labroo, A. A., \& Patrick, V. M. (2009). Psychological distancing: why happiness helps you see the big picture. Journal of Consumer Research, 35(5), 800-809.

Lamberton, C. P., \& Diehl, K. (2013). Retail choice architecture: the effects of benefit-and attribute-based assortment organization on consumer perceptions and choice. Journal of Consumer Research, 40(3), $393-411$.

Lee, H., Deng, X., Unnava, H. R., \& Fujita, K. (2014). Monochrome forests and colorful trees: the effect of black-and-white versus color imagery on construal level. Journal of Consumer Research, 41(4), 10151032.

Liberman, N., Sagristano, M. D., \& Trope, Y. (2002). The effect of temporal distance on level of mental construal. Journal of Experimental Social Psychology, 38(6), 523-534.

Liberman, N., \& Trope, Y. (1998). The role of feasibility and desirability considerations in near and distant future decisions: a test of temporal construal theory. Journal of Personality and Social Psychology, 75(1), $5-18$.

Liberman, N., Trope, Y., and Stephan, E. (2007a). Psychological distance. In A.W. Kruglanski and E.T. Higgins (Eds.), Social psychology: handbook of basic principles (pp. 353-383). New York, NY: Guilford.

Liberman, N., Trope, Y., \& Wakslak, C. (2007b). Construal level theory and consumer behavior. Journal of Consumer Psychology, 17(2), 113-117.

Lim, E. . A. C., \& Ang, S. H. (2008). Hedonic vs. utilitarian consumption: a cross-cultural perspective based on cultural conditioning. Journal of Business Research, 61(3), 225-232.

Liviatan, I., Trope, Y., \& Liberman, N. (2008). Interpersonal similarity as a social distance dimension: implications for perception of others' actions. Journal of Experimental Social Psychology, 44(5), 1256-1269.

Massara, F., Scarpi, D., \& Porcheddu, D. (2020). Can your advertisement go abstract without affecting willingness to pay?: product-centered versus lifestyle content in luxury brand print advertisements. Journal of Advertising Research, 60(1), 28-37.

Mehta, R., \& Dixit, G. (2016). Consumer decision making styles in developed and developing markets: a cross-country comparison. Journal of Retailing and Consumer Services, 33, 202-208.

Melnyk, V., Klein, K., \& Völckner, F. (2012). The double-edged sword of foreign brand names for companies from emerging countries. Journal of Marketing, 76(6), 21-37. 
Milkman, K. L., Rogers, T., \& Bazerman, M. H. (2008). Harnessing our inner angels and demons: what we have learned about want/should conflicts and how that knowledge can help us reduce short-sighted decision making. Perspectives on Psychological Science, 3(4), 324-338.

Nissan, T., Shapira, O., \& Liberman, N. (2015). Effects of power on mental rotation and emotion recognition in women. Personality and Social Psychology Bulletin, 41(10), 1425-1437.

Pennington, G. . L., \& Roese, N. J. (2003). Regulatory focus and temporal distance. Journal of Experimental Social Psychology, 39(6), 563-576.

Pfeiffer, B. E., Deval, H., Kardes, F. R., Ewing, D. R., Han, X., \& Cronley, M. L. (2014). Effects of construal level on omission detection and multiattribute evaluation. Psychology \& Marketing, 31(11), 992-1007.

Roy, R., \& Ng, S. (2012). Regulatory focus and preference reversal between hedonic and utilitarian consumption. Journal of Consumer Behaviour, 11(1), 81-88.

Sagristano, M. D., Trope, Y., \& Liberman, N. (2002). Time-dependent gambling: odds now, money later. Journal of Experimental Psychology: General, 131(3), 364-376.

Scarpi, D. (2012). Work and fun on the internet: the effects of utilitarianism and hedonism online. Journal of Interactive Marketing, 26(1), 53-67.

Scarpi, D. (2020). Hedonism, utilitarianism, and consumer behavior: Exploring the consequences of customer orientation. Springer Nature.

Septianto, F., \& Pratiwi, L. (2016). The moderating role of construal level on the evaluation of emotional appeal vs. cognitive appeal advertisements. Marketing Letters, 27, 171-181.

Shiv, B., \& Fedorikhin, A. (1999). Heart and mind in conflict: the interplay of affect and cognition in consumer decision making. Journal of Consumer Research, 26(3), 278-292.

Slepian, M. L., Masicampo, E. J., \& Ambady, N. (2015). Cognition from on high and down low: verticality and construal level. Journal of Personality and Social Psychology, 108(1), 1-17.

Smith, D., Menon, S., \& Sivakumar, K. (2005). Online peer and editorial recommendations, trust, and choice in virtual markets. Journal of Interactive Marketing, 19(3), 15-37.

Spassova, G., \& Lee, A. Y. (2013). Looking into the future: a match between self-view and temporal distance. Journal of Consumer Research, 40(1), 159-171.

Trope, Y., \& Liberman, N. (2010). Construal-level theory of psychological distance. Psychological Review, $117(2), 440-463$.

Vallacher, R. R., \& Wegner, D. M. (1989). Levels of personal agency: individual variation in action identification. Journal of Personality and Social Psychology, 57(4), 660-671.

Van der Heijden, H. (2004). User acceptance of hedonic information systems. MIS Quarterly, 28, 695-704.

Watson, D., Clark, L. A., \& Tellegen, A. (1988). Development and validation of brief measures of positive and negative affect: the PANAS scales. Journal of Personality and Social Psychology, 54(6), 1063-1070.

Vogt, C. A., \& Andereck, K. L. (2003). Destination perceptions across a vacation. Journal of Travel Research, 41(4), 348-354.

Zhang, M., \& Wang, J. (2009). Psychological distance asymmetry: the spatial dimension vs. other dimensions. Journal of Consumer Psychology, 19(3), 497-507.

Publisher's note Springer Nature remains neutral with regard to jurisdictional claims in published maps and institutional affiliations. 